\title{
ДИАТОМОВЫЕ ВОДОРОСЛИ В ОЦЕНКЕ КАЧЕСТВА ВОД ОЗЕРНО-РЕЧНОЙ СИСТЕМЫ ПАЗ
}

Денисов Д.Б., Косова А.Л.

ИППЭС КНЦ РАН, Anamumbl, proffessuir@gmail.com

\section{Введение}

Исследования пресноводных альгоценозов являются неотьемлемой составляющей комплексного экологического мониторинга водоемов. Диатомовые водоросли являются доминирующей по численности, продуктивности и таксономическому разнообразию группой водорослей в арктических внутренних водах. Их высокая чувствительность ко всем изменениям окружающей среды позволяет с высокой точностью определять экологическое состояние водоемов, степень антропогенной трансформации и регистрировать ответные реакции водных экосистем на климатические изменения. Показатели, рассчитываемые по диатомовым водорослям, входит в международные системы биоиндикации (Водная рамочная директива - WFD), которые активно разрабатываются в настоящее время. Большие перспективы открываются при использовании комплексов диатомовых водорослей поверхностных донных отложений (ДО) озер как интегрального показателя современного состояния среды. Это особенно актуально для арктической зоны, где оценка качества вод по традиционным гидробиологическим и гидрохимическим показателям может быть затруднена в силу практической невозможности синхронизировать время отбора проб в различных участках акватории или в различных водоемах. В рамках реализации международных мониторинговых программ (TEC Kolarctic) в период с 2011 по 2016 гг. были исследованы сообщества диатомовых водорослей водосборного бассейна озерно-речной системы Паз (Патсойоки), расположенного на территории трех стран - России, Финляндии и Норвегии [6].

\section{материалы и методы}

Река Паз - самая крупная река на севере Фенноскандии - в настоящее время представляет собой озерно-речную систему в результате зарегулирования стока каскадом водохранилищ семи Пазских ГЭС; длина реки составляет 167 км, площадь водосбора - 20890 км². Сама река, а также во-

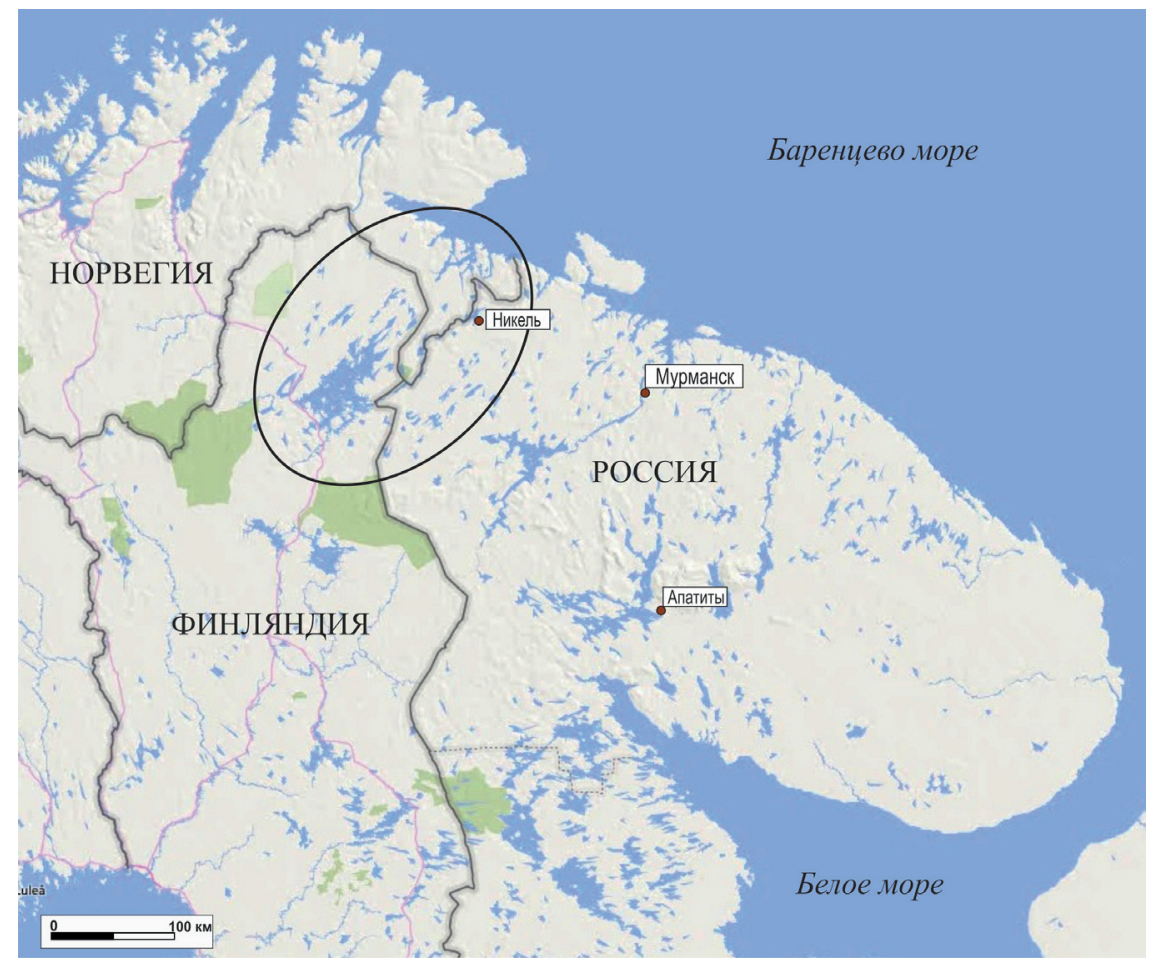

Рис. 1. Карта-схема района работ. 
доемы, расположенные в пределах ее водосборной территории, в различной степени подвержены промышленному загрязнению в результате деятельности горно-металлургической промышленности Печенгского района, а также эвтрофированию стоками населенных пунктов и сельскохозяйственных объектов.

Материалом для исследований послужили диатомовые водоросли планктона и литорального перифитона плесовых участков озерно-речной системы Паз (Скрюккебукта, Ваггатем, Раякоски и оз. Куэтсъярви), а также 23 озера на территории водосбора на территории России, Финляндии и Норвегии (за исключением оз. Инари). Для 10 водоемов были изучены диатомовые комплексы поверхностных и сформировавшихся до начала промышленного освоения региона слоев ДО. Отбор и анализ проб осуществлялся по стандартным общепринятым методикам, по схеме, принятой в ИППЭС КНЦ РАН, описанной ранее [3,4]. Для оценки качества среды использовались показатели таксономического разнообразия, экологическая структура сообществ и индекс сапробности [1]. Химический анализ проб воды и ДО был выполнен в аналитической лаборатории ИППЭС КНЦ РАН. Для анализа влияния тяжелых металлов на структуру диатомовых комплексов ДО были рассчитаны коэффициенты загрязнения тяжелыми металлами [2].

\section{Результаты и обсуждение}

В различных участках р. Паз структура сообществ, видовой состав и численные характеристики диатомового планктона характеризуется существенными различиями. Всего было обнаружено 97 таксонов диатомей рангом ниже рода. В заливе Рускебукта в 2012 г. было зафиксировано массовое развитие Urosolenia eriensis (Smith) Round \& Crawf., что свидетельствует о развитии процессов эвтрофикации этого участка акватории. U. eriensis - типичный бентосный вид, и ее переход к планктонному существованию также указывает на эвтрофикацию, что согласуется с результатами гидрохимического анализа - для залива Русскебукта характеры самые высокие для реки Пасвик концентрации биогенных веществ, в первую очередь азота (до 458 мгкN/л) и фосфора (до 75 мкгР/л).

Сотрудниками заповедника «Пасвик» в августе 2012 г. были обнаружены не типичные массивные обрастания каменистого субстрата на мелководье в районе стока водохранилища Янискоски. Было установлено, что они сформированы колониями диатомовой водоросли Didymosphenia geminata (Lyngb.) Schmidt, клетки которой в колонии растут на длинных полисахаридных стебельках, что придает обрастаниям бежево-светло-коричневый цвет. Для р. Паз впервые было зафиксировано явление, известное как «Brown plague: Didymo», представляющее собой существенную проблему для текучих вод с холодноводными условиями по всему миру в течение последних лет [5].

Структура колоний D. geminata, ассоциированных с другими диатомовыми водорослями, обуславливает образование плотных слизистых водорослевых матов на каменистом субстрате, плотно покрывающем дно. При этом, массовое развитие этого вида не требует большого количества биогенных элементов или повышенных температур воды. Этот вид является широко распространенным, однако явления массового развития регистрируются только в последние десятилетия, причем там, где не были известны до этого. В ходе образования плотных колоний, происходит нарушение естественных местообитаний типичных субарктических гидробионтов, включая бентос и ихтиофауну. Изменяются не только потенциальные нерестилища, но и трофические цепи, что определяется трансформацией бентосных сообществ. Массовое развитие D. geminata, несомненно, представляет определенную угрозу для функционирования экосистемы р. Паз. Очевидно, следует рассматривать факт развития той водоросли как свидетельство глобальных климатических изменений, проявляющихся не только в росте среднелетних температур, но и изменениях в гидролого-геохимических характеристиках водосборной площади, обуславливающих изменения в режиме обеспеченности биогенными элементами вод реки.

В 23 озерах, расположенных в различных участках водосбора р Паз было обнаружено 246 таксонов диатомовых водорослей рангом ниже рода, включая планктон, перифитон и поверхностный слой ДО. Исследованные озера характеризуются как индивидуальными гидролого-геохимическими особенностями, так и степенью антропогенной нагрузки, что определило различия в видовом раз- 
нообразии и структуре диатомей. Так, индекс разнообразия Шеннона-Уивера изменялся в диапазоне от 1.50 до 3.51 бит/экз. Доминировали виды, характерные для низко минерализованных, олиготрофных водоемов, с нейтральной или слабокислой реакцией. Индекс сапробности $(S)$, pacсчитанный по показателям диатомового перифитона позволяет отнести воды большинство озер к альфа-олигосапробной зоне [1].

Диатомовые водоросли планктона разнотипных озер водосборного бассейна реки Паз характеризуется высоким видовым богатством, неодинаковым для каждого водного объекта. Наибольшее количество видов (до 160 таксонов рангом ниже рода) характерно для озер, где сочетаются различные условия для развития водорослей, включая проточные, мелководные и глубоководные участки. Самыми бедными в таксономическом отношении оказались норвежские озера на территории Ярфьорда (менее 40 таксонов).

Наиболее резкие отличия видового состава характерны для водоемов, находящихся под воздействием антропогенных факторов, что в определенной степени согласуется с гидрохимическими данными: большинство озер на территории РФ оказались более богаты биогенными элементами $\left(\mathrm{N}_{\text {общ. }} 175\right.$ мкг/л, $\mathrm{P}_{\text {общ. }} 6.2$ мкг/л), чем норвежские $\left(\mathrm{N}_{\text {общ. }} 118\right.$ мкг/л, $\mathrm{P}_{\text {общ. }} 2.9$ мкг/л) и финские $\left(\mathrm{N}_{\text {общ. }} 128\right.$ мкг/л, $\mathrm{P}_{\text {общ. }} 3.0$ мкг/л), при этом озера Ярфьорда (Норвегия) резко отличаются повышенным содержанием хлоридов и сульфатов, обусловленным влиянием моря. Литоральные сообщества диатомей характеризуются обилием типичных субарктических видов, предпочитающих олиготрофные условия и $\mathrm{pH} \leq 7.0$ : Brachysira brebissonii R.Ross (до ), B. vitrea (Grun.) R.Ross in Hartley (до 16\%), B. zellensis (Grun.) Round \& Mann (до $6 \%$ ), Brachysira styriaca (Grun.) R.Ross (до $22 \%$ ), Denticula tenuis var. tenuis Kütz. (до 8 \%), Frustulia rhomboides (Ehrb.) De Тoni (до 19\%). Род Eunotia отличается наибольшим богатством таксонов (рис. 2). Очевидно, это объясняется связью многих исследованных водоемов с заболоченными территориями, так как многие виды рода Eunotia активно развиваются в болотах. Индекс Шеннона варьировал в диапазоне от 1.50 до 3.51 бит/экз.

Диатомовые сообщества перифитона озера Куэтсъярви резко отличаются от других изученных водоемов обилием представителей родов Fragilaria, Staurosirella и Staurosira, предпочитающих воды, обогащенные биогенными элементами: Fragilaria capucina Desm., Staurosira construens (Ehrb.) Hust., Staurosirella pinnata (Ehrb.) Will. \& Round, Fragilaria capucina, Staurosira venter (Ehrb.) Cleve \& Möll.

Диатомовые комплексы ДО предоставляют интегральную информацию о состоянии водосборной территории р. Паз. В настоящее время видовое разнообразие диатомей изученных озер во многом определяется интенсивностью антропогенной нагрузки, что подтверждает зависимость ин-

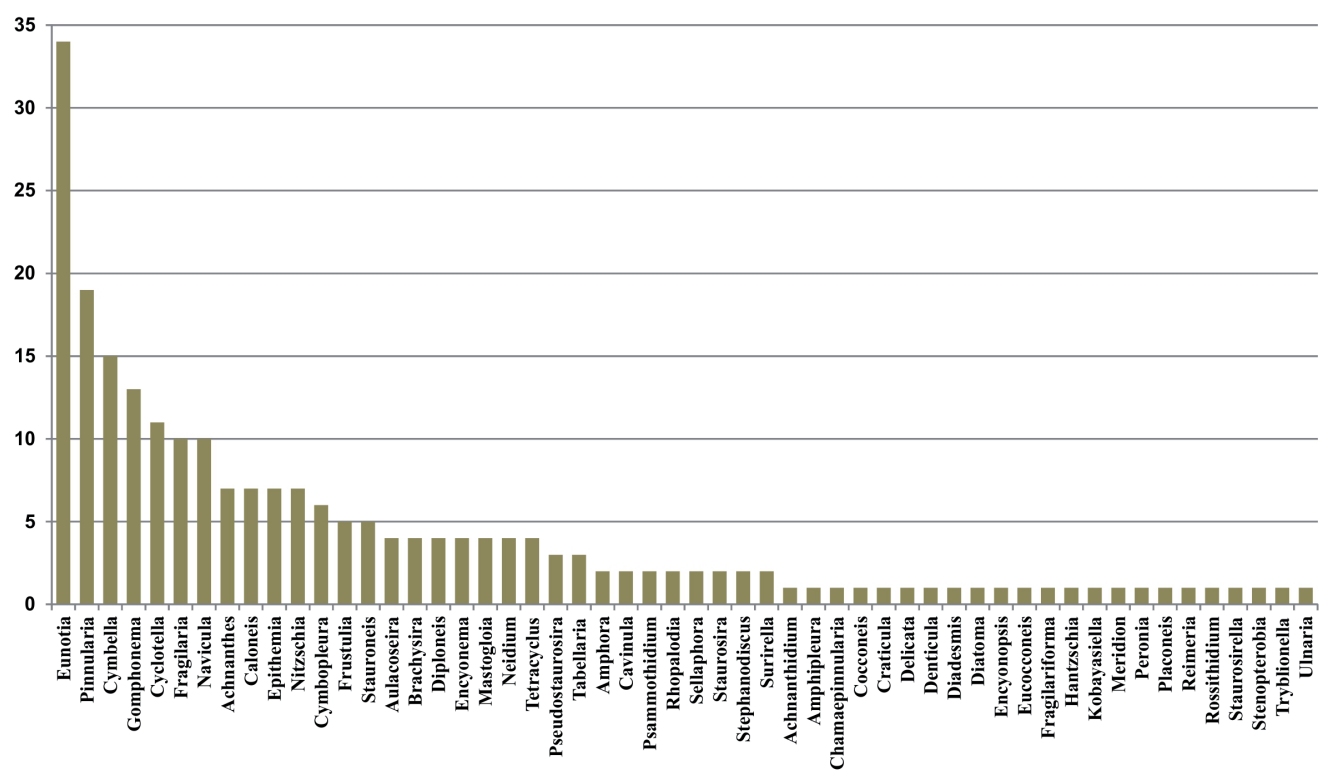

Рис. 2. Таксономический спектр диатомового перифитона разнотипных озер водосбора реки Паз. 
a)

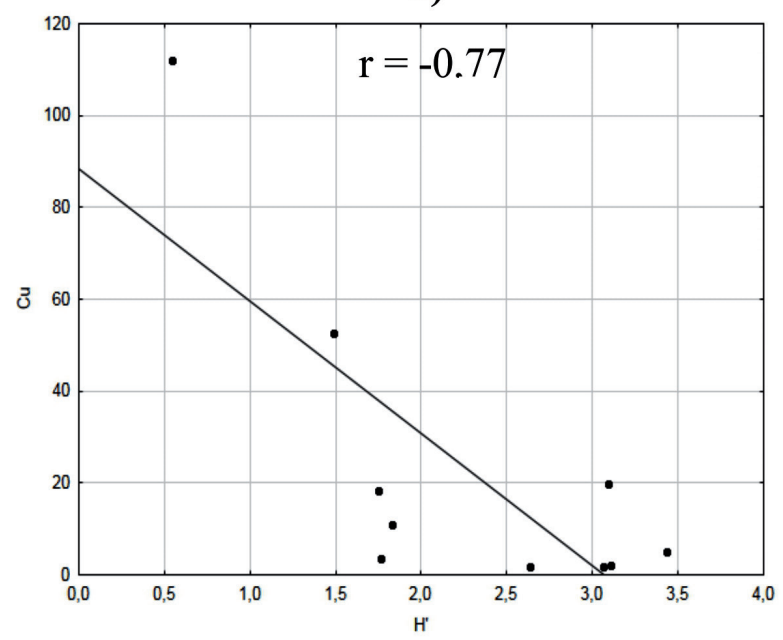

б)

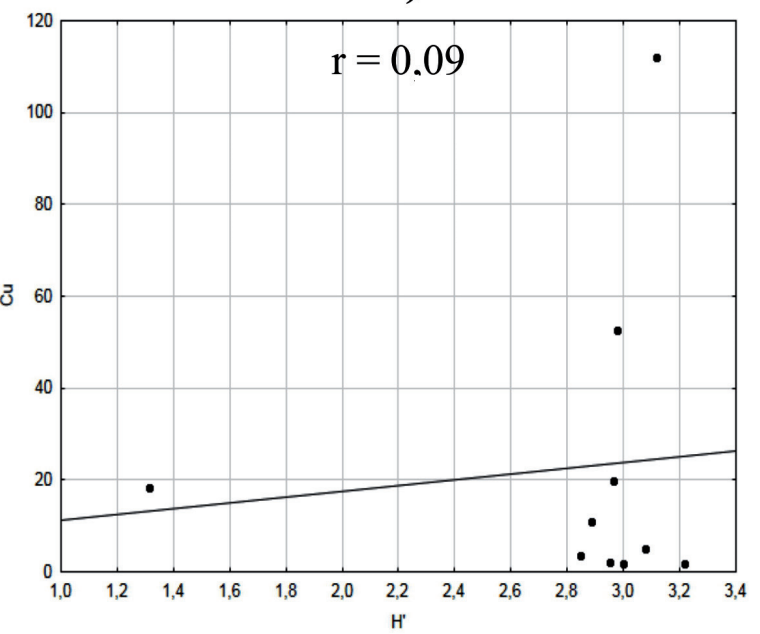

Рис. 3. Зависимость индекса видового разнообразия Шеннона-Уивера (Н') диатомовых комплексов ДО от коэффициента загрязнения медью (Cu): а) - поверхностные слои, б) - «доиндустриальные» слои.

декса Н' от коэффициента загрязнения медью - приоритетного загрязнителя исследованного района (рис. 3, а). При этом «доиндустриальные» диатомовые комплексы такой зависимости не обнаруживают (рис. 3, б). В озерах с высокими коэффициентами загрязнения по $\mathrm{Cu}$, $\mathrm{Ni}$ и $\mathrm{Cd}$ отмечается резкая смена доминирующих видов на фоне общего уменьшение видового богатства и таксономического разнообразия.

\section{Заключение}

Диатомовые водоросли водосборной территории озерно-речной системы Паз характеризуются значительным таксономическим разнообразием и составляют доминирующий комплекс видов в планктоне и перифитоне. Альгоценозы целого ряда исследованных водоемов развиваются в условиях трофической и токсической нагрузки, что отражается на численных показателях структуры сообществ. Так, в эвтрофируемых заливах реки Паз (Рускебукта) наблюдались экстремально высокие для арктических вод значения биомассы фитопланктона, обусловленные массовым развитием Urosolenia eriensis. В реке Паз зафиксировано явление «Didymо» - бурное разрастание диатомового перифитона (Didymosphenia geminata), причиной чего может быть изменение гидроголо-геохимических условий формирования качества вод на фоне глобальных изменений климатической системы Арктики. Разнотипные озера исследованной водосборной территории отличаются значительной вариабельностью условий обитания, что обуславливает значительное таксономическое разнообразие диатомей. Индекс Шеннона-Уивера (H') может быть использован в качестве интегрального показателя загрязнения тяжелыми металлами. Показано, что степень загрязнения озер приоритетными загрязнителями определяет видовое разнообразие диатомей.

\section{Литература}

1. Баринова С.С., Медведева Л.А., Анисимова О.В. Биоразнообразие водорослей-индикаторов окружающей среды. Тель-Авив: PiliesStudio. 2006. 498 с.

2. Даувальтер В.А. Геоэкология донных отложений озер. Мурманск: Мурманский гос. техн. ун-т. 2012. 242 с.

3. Денисов Д.Б. Экологические особенности водорослевых сообществ разнотипных субарктических водоемов // Вестник КНЦ РАН. №1. 2010. С. 48-55.

4. Денисов Д.Б., Кашулин Н.А., Даувальтер В.А. Диатомовые комплексы донных отложений озера Имандра в зоне влияния подогретых вод Кольской АЭС // Тр. Карельского научного центра РАН. 2015. № 9. серия «Лимнология». С 10-24.7. Диатомовый анализ. 1949. Л.: кн. 1. 240 с.; кн. 2. 238 с.

5. International Didymo Conference: new horizons in science and management (March, 12-13, 2013, Providence, Rhode, Island) / Hosted by the Invasive Species Action Network and the Northeast Aquatic Nuisance Species Panel Fiscal management provided by the Northeast Aquatic Nuisance Species Council. 2013, 44 p.

6. Ylikörkkö, J, Christensen, G.N., Kashulin, N., Denisov, D., Andersen, H.J., Jelkänen, E. Environmental Challenges in the Joint Border Area // Reports 41. Centre for Economic Development, Transport and the Environment for Lapland. Juvenes Print. 2015. 165 p. 